\title{
An Excimer-based, Binuclear, On-off Switchable Calix[4]crown Chemosensor
}

Sung Kuk Kim, ${ }^{1}$ Seoung Ho Lee, ${ }^{1}$ Ji Yeon Lee, ${ }^{1}$ Jin Yong Lee,,${ }^{2, *}$ Richard A. Bartsch, ${ }^{3}$ and Jong Seung $\operatorname{Kim}^{1, *}$

${ }^{1}$ Department of Chemistry, Institute of Nanosensor and Biotechnology, Dankook University, Seoul 140714 , Korea

\author{
${ }^{2}$ Department of Chemistry, Chonnam National University, Gwangju 500-757, Korea \\ ${ }^{3}$ Department of Chemistry and Biochemistry, Texas Tech University, Lubbock, Texas 79401 \\ * Corresponding author: jongskim@dankook.ac.kr
}

\section{Supporting Information}

\section{Contents}

Page 1: Fluorescence intensity changes $\left(I_{0}-I\right)$ of $\mathbf{1}$ and $\mathbf{2}$ with increasing $\mathrm{Pb}^{2+}$ ion concentrations in acetonitrile. (Figure S1)

Page 2: Metal ion-induced chemical shift changes of 1 in $\mathrm{CD}_{3} \mathrm{CN} / \mathrm{CDCl}_{3}$ (4/1, v/v). (a): 1 only, (b): $\mathbf{1}+$ 10 equiv. of $\mathrm{K}^{+} \mathrm{ClO}_{4}^{-}$, (c): $\mathbf{1}+10$ equiv. of $\mathrm{Pb}^{2+}\left(\mathrm{ClO}_{4}^{-}\right)_{2}$. (Figure S2)

Page 3: UV Frontier molecular orbitals (HOMO, LUMO, LUMO2, and LUMO3) of (a) $\mathbf{1}$, (b) $\mathbf{1} \bullet \mathrm{Pb}^{2+}$, and (c) $\mathbf{1} \cdot \mathrm{K}^{+}$. (Figure S3) 


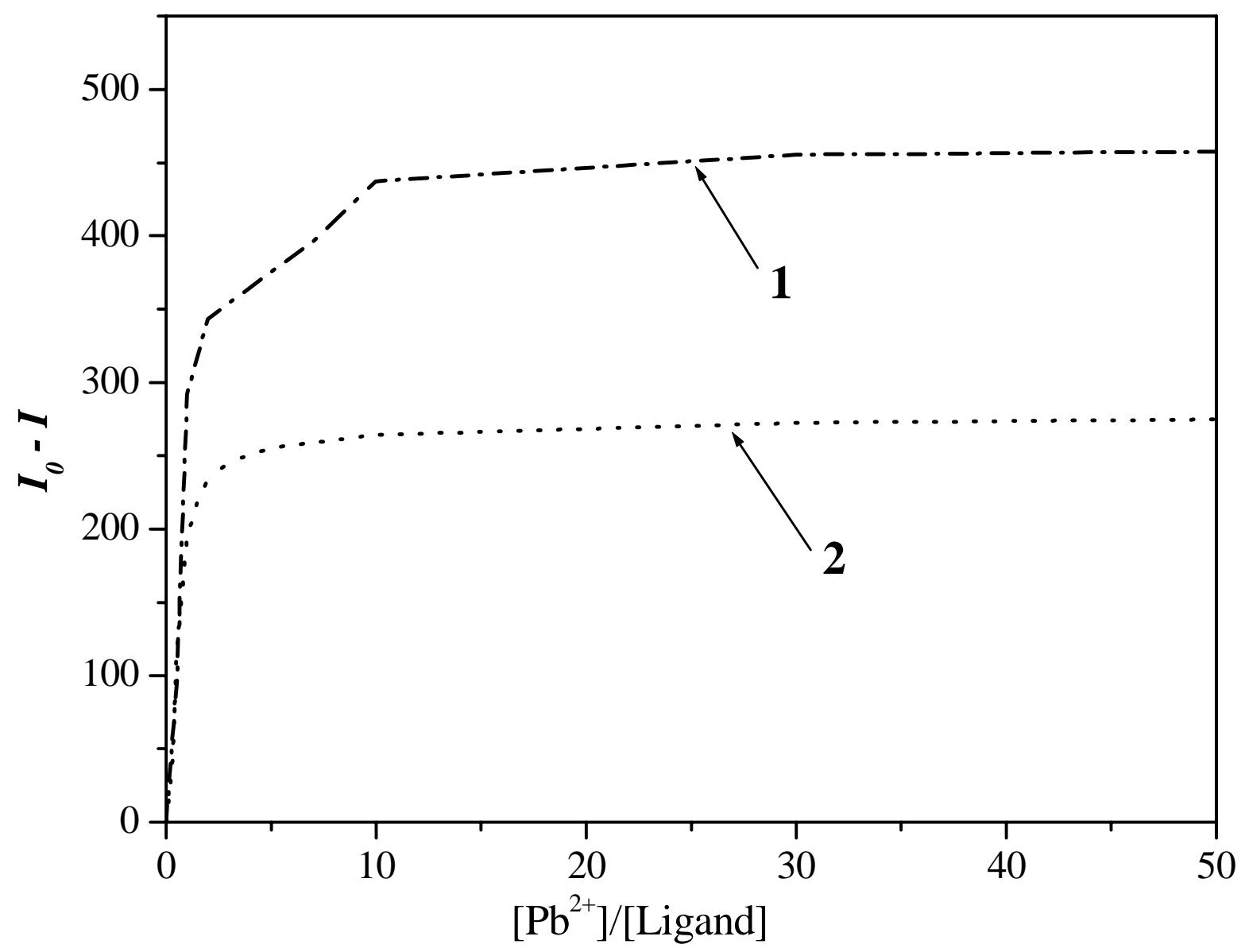

Figure S1. Fluorescence intensity changes $\left(I_{0}-I\right)$ of $\mathbf{1}$ and $\mathbf{2}$ with increasing $\mathrm{Pb}^{2+}$ ion concentrations in acetonitrile. $I_{0}$ : fluorescence emission intensity of uncomplexed $\mathbf{1}$ and $\mathbf{2}$; $I$ : fluorescence emission intensity of metal ion-complexed $\mathbf{1}$ and $\mathbf{2}$ 

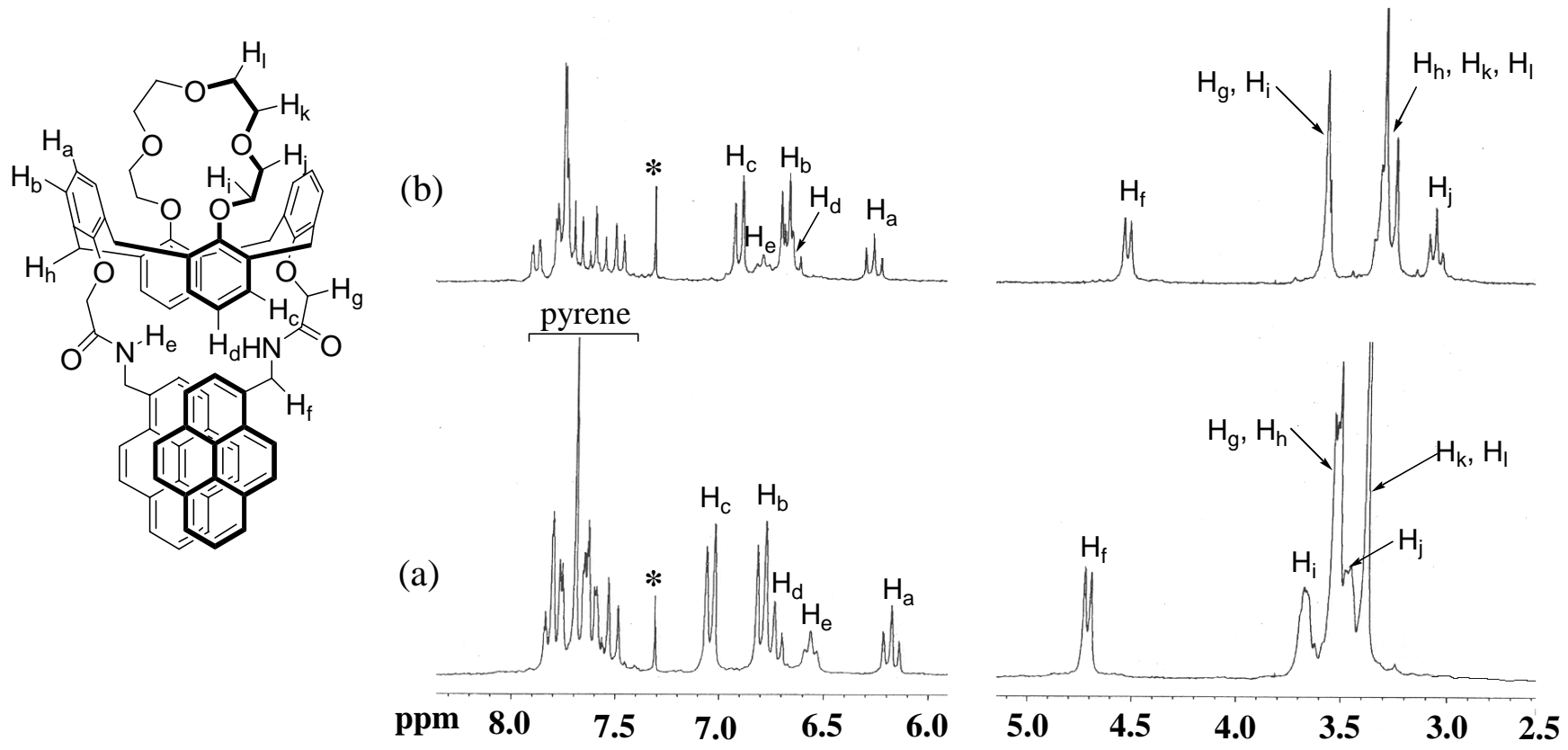

Figure S2. Metal ion-induced chemical shift changes of 1 in $\mathrm{CD}_{3} \mathrm{CN} / \mathrm{CDCl}_{3}(4 / 1, \mathrm{v} / \mathrm{v})$. (a): 1 only, (b): $\mathbf{1}+10$ equiv. of $\mathrm{K}^{+} \mathrm{ClO}_{4}^{-}$, (c): $\mathbf{1}+10$ equiv. of $\mathrm{Pb}^{2+}\left(\mathrm{ClO}_{4}^{-}\right)_{2}$. * denotes NMR solvent peaks. 


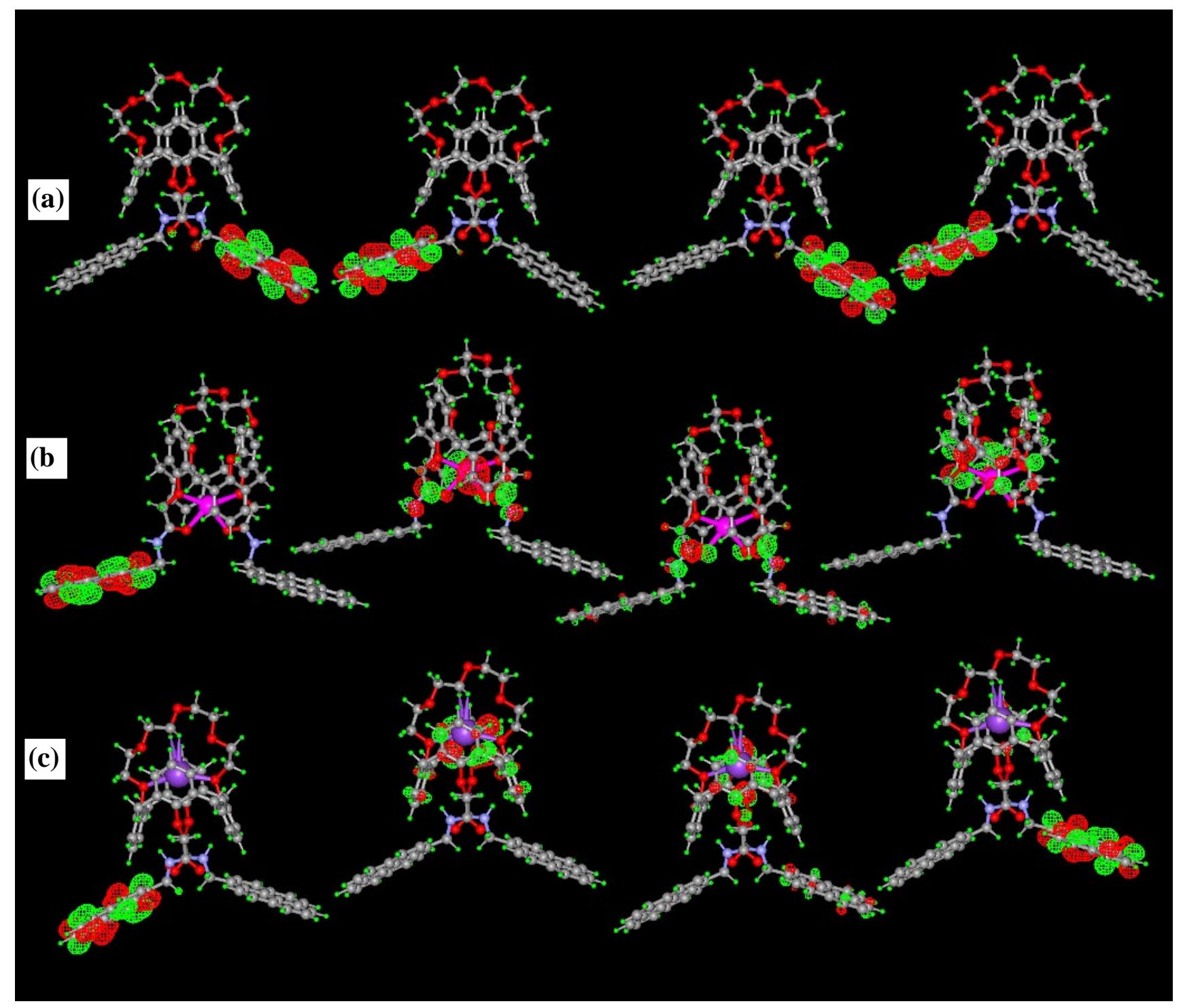

Figure S3. Frontier molecular orbitals (HOMO, LUMO, LUMO2, and LUMO3) of (a) $\mathbf{1}$, (b) $\mathbf{1} \cdot \mathrm{Pb}^{2+}$, and (c) $\mathbf{1} \cdot \mathrm{K}^{+}$. 